\title{
Management of Diabetic Nephropathy in the Elderly: Special Considerations
}

\author{
Emaad M. Abdel-Rahman', Tarek Alhamad ${ }^{2}$, Brian Reeves $\mathbf{W}^{2}$ and Alaa S. Awad ${ }^{2 *}$
}

${ }^{1}$ Department of Medicine, Division of Nephrology, University of Virginia, Charlottesville VA, USA

${ }^{2}$ Department of Medicine, Division of Nephrology, Penn State Hershey Medical Center, Hershey PA, USA

\begin{abstract}
The incidence and prevalence of End-Stage Renal Disease (ESRD) secondary to Diabetic Nephropathy (DN) have been progressively increasing, reaching pandemic proportions over the past 20 years. Diabetes mellitus is responsible for more than $40 \%$ of all cases of ESRD in the United States. Despite that, the treatment of DN is still suboptimal. Both the elderly and diabetic populations are among the fastest growing categories. While several guidelines are available for management of DN in the general population, elderly patients have unique characteristics that may require adaptation of the general therapeutic guidelines used for the general population. Current therapy directed at delaying the progression of DN in elderly includes optimal glycemic and blood pressure control, proteinuria/albuminuria reduction, interruption of the renin-angiotensin-aldosterone system through the use of angiotensin converting enzyme inhibitors and angiotensin type-1 receptor blockers, along with dietary modification and cholesterol lowering agents. This review highlights the available standard therapeutic approaches to manage progressive DN in elderly.
\end{abstract}

\section{Introduction}

Diabetes Mellitus (DM) is a common disease in elderly, as more than half of all diabetic individuals in the United States are over 60 years of age. The prevalence of DM peaks in persons between 65 to 74 years of age $[1,2]$. The elderly are defined as individuals 65 years of age or older [3]. This definition remains controversial. While this definition is based solely on chronological age, other factors such as the general health of the individual as well as the presence/absence of associated comorbidities likely will play an important role in further defining the concept of 'elderly' [3]. Caution should be applied while managing diseases, such as DM, in this population as they are more likely to have injurious falls, polypharmacy, cognitive impairment and depression.

A large source of morbidity and premature mortality in DM relates to the development of late complications affecting multiple organ systems. Elderly patients with diabetes have the same kind of complications as younger patients. One of these complications, Diabetic Nephropathy (DN), has become the leading cause of End Stage Renal Disease (ESRD) in the United States [4].

DN and ischemic vascular nephropathy represent more than $50 \%$ of all the cases of end stage renal failure after the age of 65 yrs in the Western countries and probably worldwide [5].

$\mathrm{DN}$ is defined by persistent pathological albuminuria $(>300 \mathrm{mg}$ of urinary albumin excretion in a 24-hour collection) and abnormal renal function as recognized by an abnormal Plasma Creatinine (PCr) level or Glomerular Filtration Rate (GFR) [6]. Several other factors need to be considered to reach the diagnosis of $\mathrm{DN}$ as the duration of DM and the presence of diabetic vasculopathies. Although both DM Type-1 (DMT1) and Type-2 (DMT2) lead to DN, DN in the elderly is mainly due to DMT2. It usually takes 5 to 10 years for DMT2 individuals to develop nephropathy. However, the diagnosis is often delayed until some other event stimulates medical attention. The earliest renal manifestation of diabetes is glomerular hyperfiltration, followed by a decline in GFR and increased albuminuria usually 5 or more years after the onset of DM. Finally, overt albuminuria develops and GFR continues to fall. Hypertension, which tends to develop after microalbuminuria in DMT1, is usually present as the time nephropathy develops in DMT2 [7].
The exact pathogenesis of DN is complex and not completely understood. Among the pathogenic factors are: hyperglycemia, increased systemic and glomerular pressure, increased activity of the Renin-Angiotensin-Aldosterone-System (RAAS) and stimulation of several cytokines and growth factors by metabolic and hemodynamic factors [8]. Several therapeutic interventions targeting these mechanisms have been developed and implemented with various degrees of success.

Elderly persons with diabetes might be fit and healthy, residing independently, or frail with functional disabilities and residing in assisted care facilities or in nursing homes. Therefore, therapies need to take into consideration the overall health, functional status, comorbidities and life expectancy of each individual. A geriatric evaluation of cognitive functions and autonomy for daily living activities may be helpful in assessing the ability of the patient to comply with his/her treatment plan.

\section{Current Therapeutic Strategies for DN in Elderly}

Available therapeutic options directed at delaying the progression of DN include Blood Glucose (BG) control, Improved Blood Pressure (BP) control, interruption of the RAAS using Angiotensin-Converting Enzyme Inhibitors (Acei) and/or Angiotensin Type-1 (AT1) Receptor Blockers (ARBs) along with dietary modification and cholesterollowering agents.

\section{Lifestyle modification}

Although these modifications are often neglected, they are important components of the management of DN. These modifications

*Corresponding author: Alaa S. Awad, Department of Medicine, Division of Nephrology, Penn State Hershey Medical Center, Hershey PA, USA, Tel: 717-5311713; Fax: 717-531-6776; E-mail: asa17@psu.edu

Received June 11, 2011; Accepted July 30, 2012; Published August 03, 2012

Citation: Abdel-Rahman EM, Alhamad T, Brian Reeves W, Awad AS (2012) Management of Diabetic Nephropathy in the Elderly: Special Considerations. J Nephrol Therapeut 2:124. doi:10.4172/2161-0959.1000124

Copyright: (c) 2012 Abdel-Rahman EM, et al. This is an open-access article distributed under the terms of the Creative Commons Attribution License, which permits unrestricted use, distribution, and reproduction in any medium, provided the original author and source are credited. 
include exercise as tolerated, smoking cessation, decrease in alcohol consumption, and weight reduction in overweight patients [9]. Smoking is an independent risk factor for the development of nephropathy in patients with DMT2, and smoking cessation alone may reduce the risk of disease progression by 30 percent [10]. Although alcohol consumption is associated with risk of proliferative retinopathy, neuropathy and macroalbuminuria, yet previous report showed that moderate alcohol consumption is associated with a lower risk of all microvascular complications among type 1 diabetes patients [11]. The elderly may represent a unique challenge to lifestyle modification. While they still may benefit from smoking cessation or decreasing alcohol consumption, some of these interventions might not be applicable in elderly patients with anorexia [12,13], or in frail elderly.

\section{Glucose control}

Target blood glucose: Older patients with DMT2 are a very heterogeneous group with multiple co-morbidities, an increased risk of hypoglycemia, and a greater susceptibility to adverse effects of hypoglycemic drugs, making treatment of DMT2 in this population challenging [14]. There is an increased risk of falling and many have a decline in their functional status. Thus, hypoglycemia may result in an increased risk of traumatic falls or exacerbation of co-morbid conditions. Therefore, identifying the optimal blood glucose target for the elderly is crucial.

The ACCORD (the Action to Control Cardiovascular Risk in Diabetes) trial randomized 10,251 participants (mean age 62.2 years) with a median glycated hemoglobin of $8.1 \%$ to a strategy of intensive glycemic control (Hemoglobin A1c (HbA1c) target $<6.0 \%$ ) or standard control (HbAlc target 7.0\%-7.9\%). Compared with standard therapy, intense treatment yielded increased mortality and did not significantly reduce major cardiovascular events [15]. The ADVANCE [16] (Action in Diabetes and Vascular Disease: Preterax and Diamicron Modified Release Controlled Evaluation) and VADT [17] (Veterans Affairs Diabetes Trial) trials also compared standard and intensive glycemic control. Although these trials did not find an increase in mortality in the intense treatment arms, they also did not find a benefit of intense glycemic control in terms of mortality or a reduction in major cardiovascular events. Therefore, the American Diabetes Association (ADA) suggests that clinicians should consider less stringent HbAlc goals in the elderly than the usual target of less than 7.0\% [9]. An individualized target of $\mathrm{HbAlc}$ should take into consideration the general health and life expectancy of the elderly patient. Relatively healthy older adults with no major co-morbidities may benefit from more intense glucose control (target $\mathrm{HBA} 1 \mathrm{C}<7 \%$ ), while more lenient targets may be more appropriate for elderly with major co-morbidities, established diabetic end-organ damage or limited life expectancy.

Hypoglycemic agents and doses: Besides identifying the optimal blood glucose levels for the elderly, caution may need to be applied regarding the selection and the dosage of specific hypoglycemic agents in the elderly. The doses of oral hypoglycemic agents and insulin may need to be decreased as the renal function declines, and more so in the elderly, to avoid hypoglycemia and other side effects [18]. There are several reasons for a reduced insulin requirement in the elderly with advanced kidney disease; a reduced renal catabolism of insulin, anorexia that is common in these patients and impaired renal neoglucogenesis.

Metformin is associated with a small risk of lactic acidosis but is generally well tolerated in the elderly and has a minimal risk of hypoglycemia when used as monotherapy. The risk of lactic acidosis is higher in patients with renal insufficiency so renal function should be assessed prior to starting metformin. Though Duong and colleagues argued that using metformin at stable creatinine clearances as low as $20 \mathrm{ml} / \mathrm{min}$ is safe as long as metformin dosage is reduced in renal impairment and only increased after consideration of the blood glucose and plasma lactate levels, caution should be exercised when using that drug in patients with chronic kidney disease (CKD) [19].

Thiazolidinediones may induce fluid retention, edema, and congestive heart failure. A study in individuals more than 66 years of age showed that treatment with rosiglitazone was associated with an increased risk of congestive heart failure, acute myocardial infarction, and mortality when compared with combinations of other oral hypoglycemic agents [20]. Long acting sulfonylureas (carbutamide, glyburide and glimepiride) are associated with an increased risk of hypoglycemia in elderly patients. In general, sulfonylureas should be used with caution when GFR is less than $60 \mathrm{ml} / \mathrm{min}$, and should be avoided if possible when the GFR is less than $30 \mathrm{ml} / \mathrm{min}$. On the other hand, Dipeptidyl Peptidase-4 (DPP-4) inhibitor dosage was found to be unaffected by age [21]. Several studies showed that DPP-4 inhibitors were well tolerated with no hypoglycemic episodes in the elderly [22], even those with moderate to severe renal disease [23]. Glucagon-Like Peptide-1 (GLP-1 analogs) as exanetide and liraglutide are also welltolerated in the elderly and carry a low risk of hypoglycemia.

Pancreas transplantation is generally restricted to younger individuals with DMT1 and is not an option for elderly individuals with DMT2.

In summary, glycemic treatment in both DMT1 and DMT2 reduces the risk and progression of DN. The specific goal for HbAlc, the selection of hypoglycemic agents and dosing of these agents should be individualized considering the potential benefits and harms of different levels of $\mathrm{HbAlc}$ as well as the hypoglycemic drug used. Healthy older adults may benefit from intense glucose control (HbA1c $<7 \%)$, while for more debilitated older adults a higher HbAlc higher target may be preferable.

\section{Blood pressure control}

Approximately $40 \%$ of patients with DMT2 at the age of 45 are hypertensive; the proportion increases to $60 \%$ by the age of 75 [24] Both systolic and diastolic hypertension markedly accelerate the progression of DN. Normotensive patients with advanced DN show slower progression compared with hypertensive patients of all ages [25-34]. Several randomized controlled trials indicate that multiple antihypertensive agents, often more than three, are commonly required to achieve optimal BP control [27,35-38]. Non-pharmacologic approaches (dietary modifications, weight loss and increased physical activity) are effective in reducing BP in non-diabetic individuals [39] and may have similar benefits for diabetic patients. However, pharmacologic approaches remain the mainstay for controlling BP in patients with DM $[40,41]$.

Target BP: The optimal target BP for patients with DN continues to be debated [42]. The recent ACCORD trial (mean age 62.2 years) failed to show a reduction in cardiovascular events but rather showed increased rates of hyperkalemia and renal dysfunction when targeting a systolic BP $<120 \mathrm{mmHg}$ as compared with $<140 \mathrm{mmHg}$ 
[43]. Likewise, the ABCD trial (Appropriate Blood Pressure Control in Diabetes) found no benefit in renal function (but a reduction in albuminuria) of a target SBP of 120 vs. $140 \mathrm{mmHg}$ [26]. A subgroup analysis of 6400 patients with diabetes in the INVEST (International Verapamil-Trandolapril Study) study [44] (mean age 66 years) and a cross-sectional analysis of patients in the Swedish National Diabetes Registry [45] also failed to show a reduction in mortality in patients with systolic $\mathrm{BP}<130$ vs. $130-139 \mathrm{mmHg}$. These observations do not support BP goals of $<130 / 80$ and even bring into question the need to reduce systolic BP below $140 \mathrm{mmHg}$. The American Diabetes and Aging Guidelines (ADAG) [46] and European Diabetes and Aging Guidelines (EDAG) [47] suggest that a BP of 140/80-90 mm Hg should be the threshold to begin BP treatment in older patients with DMT2. A lower target was suggested for patients with CKD.

It might be worth noting that it is important to have different systolic targets according to different clinical conditions. For instance, patients with heart failure or stroke need to have lower targets than others. Hypotension is a huge concern for elderly, as this increases the risk of falls. The risk of hypotension is further increased in diabetics due to autonomic dysfunction [48]. Therefore, a BP goal of 140/80 seems to be reasonable in frail older adults. A gradual decrease of BP is an essential strategy in treating elderly with hypertension to avoid lightheadness, dizziness and subsequent falls.

- Summary: The ADAG and EDAG recommend threshold BP of $140 / 80-90 \mathrm{mmHg}$ to start treatment in the elderly. Given the difficulty in achieving a low BP target, the risk of hypotension and falls, and the lack of strong evidence of benefit from reducing systolic $\mathrm{BP}$ to $<130$ vs. $140 \mathrm{mmHg}$, we believe that a target of 140/80-90 mmHg is a reasonable goal for the frail elderly. A BP target of $130 / 80 \mathrm{mmHg}$ can be pursued in healthy older patients who tolerate their antihypertensive regimens well, patients with significant proteinuria (over $500 \mathrm{mg} /$ day) and patients at particularly high risk of stroke.

\section{Antihypertensive agents:}

\section{- Agents affecting renin-angiotensin-aldosterone-system :}

- ACEi/ARBs: Activation of the RAAS system plays a crucial role in the pathophysiology of DN. Several trials have established the efficacy of ACEi and ARBs in reducing the progression of DN $[49,50]$. The micro-HOPE study, a subgroup analysis of HOPE (Heart Outcomes Evaluation Prevention), revealed that $10 \mathrm{mg}$ of ramipril compared with placebo in 1808 patients with DMT2 and a mean age of 65.3 years reduced the risk of overt nephropathy by $25 \%$ and that of cardiovascular death by $37 \%$. The beneficial effects of RAAS blockade go beyond a reduction in systemic BP and include a reduction of intraglomerular pressure and proteinuria, thereby slowing progression of CKD [49,50]. The Telmisartan Randomized Assessment Study in ACEi intolerant subjects with cardiovascular Disease (TRANSCEND) included patients with a mean age of 65 years who had known cardiovascular disease or diabetes with endorgan damage but without macroalbuminuria or heart failure. Patients were treated with either an ARB (Telmisartan) or a placebo in addition to standard treatment, and composite renal outcomes; dialysis, doubling of serum creatinine, changes in estimated GFR, or in albuminuria were followed. Albuminuria increased less with telmisartan than with placebo ( 32 versus
63\%; $\mathrm{p}=0.001$ ), with no significant difference in the composite renal outcome (1.96 versus $1.55 \%$ ) [51]. Furthermore, the RENAAL study (Reduction of End points in NIDDM with the Angiotensin II Antagonist Losartan) included 1513 participants, 421 (27.8\%) of whom were older than 65 years, and showed that losartan reduced the risk of ESRD by $50 \%$. The ADVANCE trial showed that the addition of an ACEi (perindopril) resulted in a reduction in proteinuria and cardiovascular death in DMT2 [29]. The DETAIL (Diabetics Exposed to Telmisartan and Enalapril) study compared an ACEi and ARB in DMT2 and found no significant differences in renal outcomes or mortality [52]. Therefore, both ACEi and ARBs appear to be equally effective in slowing the progression of DN in the elderly. Other factors, such as cost or side-effects, should dictate the selection of either class of agents.

Elderly individuals have unique characteristics that make them more liable to experience adverse renal effects with the use of agents that block the RAAS. There is a greater potential risk for further deterioration of renal function in the elderly, especially in patients with advanced CKD. A recent study by Ahmed et al. [53] evaluated the impact of discontinuing RAAS blockers in elderly patients (mean age 73.3 years) with stage 4 and 5 CKD and found an improvement in estimated GFR from 16.38 to $26.60 \mathrm{ml} / \mathrm{min}$ by 12 months after stopping these agents, suggesting that RAAS blockers contribute to further decline in GFR in elderly patients with advanced CKD. Although this study was limited in the number of patients studied $(n=52)$, it highlights the need to be cautious when using RAAS blockers in the elderly with advanced CKD.

The adverse effects that are most concerning with RAAS-blocking agents in the elderly are Acute Kidney Injury (AKI), hyperkalemia, and hypotension. Elderly individuals have a higher risk of AKI with use of RAAS blockers, especially in the setting of renovascular disease, volume depletion and hypotension. The use of such drugs was estimated in one study to account for $36 \%$ of the elderly hospitalized with AKI [54]. Furthermore, old age is associated with a decrease in plasma renin activity and low plasma aldosterone levels [55], which predisposes the elderly to hyperkalemia. The increased use of Non-Steroidal AntiInflammatory Drugs (NSAIDS) in this population compounds the risk of hyperkalemia. Elderly patients with stage 3 and 4 CKD had a higher percentage of systolic and diastolic hypotensive episodes [54]. Hypotension would be another point to avoid in elderly, as adding this medication might add further risk for falls.

A second unresolved issue centers on the efficacy of combined therapy with both ACEi and ARBs in slowing DN. Small trials had reported greater reductions in proteinuria and even slowing of renal dysfunction in patients treated with combined therapy as compared to monotherapy [56]. The enthusiasm for this approach was dampened by the ONTARGET (Ongoing Telmisartan Alone and in combination with Ramipril Global Endpoint Trial) trial which included patients more than 65 years, in which the combination therapy arm showed worse renal outcomes (doubling of the SCr and the need for dialysis), as compared with either of the monotherapy arms [57]. Most subjects in the study had non-nephrotic range proteinuria, leaving the question about whether or not; double RAAS blockers play a therapeutic role in patients with nephrotic range proteinuria unanswered. Thus, unless new data emerge supporting the use of dual therapy with ACEi and ARBs, monotherapy with either agent will remain the first-line 
for patients with DN. Even so, combination ACEi and ARB seems reasonable for selected patients, such as those with no history of hypotension or major cardiac disease, who have persistent proteinuria on ACEi or ARB monotherapy. In such circumstances, referral to a nephrologist is appropriate.

- Renin inhibitors: The benefit of blocking the RAAS with ACEi and $\mathrm{ARBs}$ in a variety of kidney diseases, including DN, is now well established [58-65]. However, such treatment does not completely abrogate the progression of kidney disease [64-66]. This partial response has been attributed in part to feedback effects, such as angiotensin-escape and aldosterone-escape $[67,68]$. In light of these phenomena, alternative approaches to optimize the RAAS-blockade are being sought. The activity of renin, the rate-limiting-step in the RAAS cascade, is increased when either ACEi or ARBs are used for prolonged periods. Thus, direct inhibition of renin activity has potential advantages over ACEi and ARBs. Not only does renin inhibition lower BP through its action on the RAAS, it has also additional direct actions mediated through a renin receptor [69]. Aliskiren, an orally active non-peptidic renin inhibitor, decreases plasma renin activity, although renin concentration is increased [7072]. Therefore, aliskiren may cause more complete RAASblockade and reduce the compensatory feedback as compared to ACEi/ARBs. Parving et al. [73] performed a prospective randomized study of aliskerin in 599 patients in patients with DMT2 who had hypertension and proteinuria (mean age of 60 yrs). They found that dual RAAS-blockade with aliskerin and losartan reduced albuminuria $20 \%$ more than losartan alone despite a very small difference in BP. Thus, renin inhibitors may be effective in delaying the progression of DN. However, better outcome data on renal function itself, rather than surrogate end points as proteinuria, are needed.

The safety and tolerability of aliskiren in elderly patients has been evaluated in several trials [74-78]. These studies showed that aliskiren lowers BP effectively and is well tolerated, even in patients $>75$ years old. Aliskiren treated patients had a higher risk of hyperkalemia compared with ACEi or thiazides [79-82] but no events of renal dysfunction. In addition, the Aliskiren Observation of Heart Failure Treatment (ALOFT) trial demonstrated that the addition of aliskiren to an ACEi (or an ARB) and a beta blocker in patients with heart failure was also well tolerated with only a small and not significant risk of hyperkalemia or hypotension [83]. Thus renin inhibitors may have a role in renoprotection in diabetic elderly, but further studies are needed.

Aldosterone antagonists: The mineralocorticoid receptor antagonists spironolactone and eplerenone reduce proteinuria when administered alone and have additional antiproteinuric benefits when given with ACEi or ARBs [84-85]. This additive antiproteinuric benefit is independent of further BP reduction $[74,75,84,86]$. The lack of sexual side-effects of eplerenone makes it a good alternative to spironolactone, particularly in men. These results, if supported by long-term outcomes, indicate that mineralocorticoid antagonists may be a valuable addition to our armamentarium to delay progression of DN with close monitoring of serum potassium and creatinine.

Whereas a previous study showed adverse effects of aldosterone antagonists in elderly patients to be infrequent, other studies contradicted those findings. The Randomized Aldactone Evaluation
Study (RALES) reported that spironolactone reduced sudden cardiac death and death from progressive heart failure in patients with severe heart failure with minimal serious adverse effects. Setting high cut-offs, the investigators noted that serious hyperkalemia was minimal (serum potassium $>6.0 \mathrm{mmol} / \mathrm{L}$ in $2 \%$ ), and that renal insufficiency (creatinine $>4.0 \mathrm{mg} / \mathrm{dl}$ ) did not occur [76]. Subsequently, smaller studies reported that spironolactone-induced hyperkalemia and renal insufficiency are more common in elderly patients than reported in RALES [79-80]. It is worth noting that those studies were not randomized, controlled trials and that different patient characteristics might explain the contradictions between those studies.

In the Eplerenone Post-Acute Myocardial Infarction Heart Failure Efficacy and Survival Study (EPHESUS), patients (mean age of 64 years) were randomly assigned to receive eplerenone $(25 \mathrm{mg} / \mathrm{d}$ initially, titrated to a maximum of $50 \mathrm{mg} / \mathrm{d}$ ) or placebo [81]. The addition of eplerenone resulted in additional reductions in overall and cardiovascular mortality and the rate of death from cardiovascular causes. Whereas hyperkalemia (serum potassium $>6.0 \mathrm{mmol} / \mathrm{L}$ ) occurred more frequently in the eplerenone group than in the placebo group ( 5.5 versus $3.9 \%$; $=0.002$ ), the incidence of severe hyperkalemia ( $>7$ and $>8 \mathrm{mmol} / \mathrm{L}$ ) was similar in both groups. Although not primarily designed as studies of elderly patients, several other studies that included patients who were a mean age of 65 years showed that use of spironolactone or eplerenone in this older population was tolerated and safe $[77,81,82]$. We still do recommend frequent monitoring of potassium levels as well as renal function in elderly diabetics receiving aldosterone inhibitors. Further studies in elderly diabetics are needed.

- 2-Agents that do not interrupt renin-angiotensinaldosterone-system: As discussed, agents which interrupt the RAAS are recommended as first line treatment of hypertension in elderly individuals with diabetes. However, the reduction in $\mathrm{BP}$ per se, rather than the choice of specific BP agents, is of paramount importance in delaying the progression of renal disease in DN40. Therefore, patients who are intolerant to ACEi and/or ARB, or who need further reduction of BP beyond what can be achieved with these drugs, will require treatment with other classes of antihypertensive agents.

- Calcium Channel Blockers (CCB): Tuomilehto et al. [78] found earlier that Dihydropyridine Calcium-Channel-Blockers (DHP CCB) are safe in elderly diabetic patients, and that they reduced mortality and cardiovascular events in patients $>60$ year old. Yet, they were found to be inferior in reducing proteinuria when compared to ACEi while achieving the same effects on blood pressure control. On the other hand, NonDihydropyridine Calcium-Channel-Blockers (NDHP CCBs) were found to reduce proteinuria and slow the progression of kidney disease in diabetics [87-90]. Bakris et al. [91] showed that NDHP CCBs were comparable to ACEi and superior to beta-blockers in reducing proteinuria and delaying progression of renal disease in elderly patients (mean age of 63) with DN. This superiority of NDHP CCBs over beta-blockers was also confirmed in African Americans with DN with mean age of 6192. Therefore, when elderly diabetic patients with albuminuria and nephropathy are unable to tolerate ACEIs or ARBs, Nondihydropyridine Calcium Channel Blockers (DCCBs), such as diltiazem or verapamil could be used. 
- Beta-blockers and diuretics: Relatively few studies have examined the effects of beta-blockers and diuretics in elderly patients with DN. Nielson and colleagues showed that though ACEi were superior to beta-blockers in reducing proteinuria; both drugs equally reduced the decline in kidney function in patients with mean age of 60-93. Likewise, the UKPDS study in patients with mean age of 56 showed that ACEi and betablockers were equally effective in reducing both macrovascular and microvascular complications in DMT [92-94].

Diuretics (chlorthalidone) are effective in preventing major cardiovascular events in diabetic and non diabetic elderly patients [95]. However, less is known regarding the effects of diuretics in patients with DN. In one study, the diuretic agent indapamide was equivalent to enalapril in reducing microalbuminuria in hypertensive diabetic patients with mean age of 60 [96]. Although the GUARD study [97] in a younger-elderly population (mean age 57.7) showed that a combination of ACEi with hydrochlorothiazide resulted in a greater reduction in albuminuria than did the combination of ACEi and DHP CCB, the larger ACCOMPLISH study [98] that was performed in a somewhat older population (mean age $=68$ years) showed that the same combination of ACEi/hydrochlorothiazide was less effective than the $\mathrm{ACEi} / \mathrm{CCB}$ combination in reducing the decline in GFR in high risk, mainly diabetic, hypertensive patients.

These studies suggest that while beta-blockers and diuretics may be helpful in the management of DN in elderly, they should probably be used in combination with ACEi or ARBs.

Dyslipidemia and lipid-lowering drugs: Cardiovascular disease is the leading cause of death in patients with advanced CKD [99]. Both DMT1 [100] and DMT2 [101] are associated with dyslipidemia; mainly hypertriglyceridemia. Lipid control in elderly persons who have diabetes, living in nursing homes often is inadequate [102,103]. Several studies showed marked cardiovascular benefits for treating dyslipidemia in patients with DM [104-111]. Post-hoc analysis of the "Heart Protection Study" (HPS) [107] which included patients who had diabetes and were between 40 and 80 years showed marginally significant reductions in the relative-risk of cardiovascular events in diabetic patients with CKD. However, these patients had primary cardiovascular disease with coincidental mild chronic kidney disease, rather than primary renal disease. On the other hand, The SHARP trial studied more than $9270 \mathrm{CKD}$ and hemodialysis patients with mean age of 62 over a 5 year period to determine the effects of simvastatin and ezetimibe in comparison to placebo. $23 \%$ of patients had diabetes. The SHARP trial showed that simvastatin and ezetimibe reduced the rate of major atherosclerotic events, but disappointingly, had no benefit on survival or CKD progression [112]. Therefore, the decision to treat with lipid-lowering drugs (statin and ezetimibe) should be based on the LDL level.

Multifactorial intervention and ASA: A recent Danish study [113] examined the impact of a multifactorial intervention on the risk of cardiac and renal outcomes in patients with DMT2 and microalbuminuria. Patients were treated with either conventional therapy or an intensive regimen consisting of tight glucose control, RAAS-blockers, aspirin, and lipid-lowering agents. The mean treatment period was 7.8 years followed by a mean of 5.5 year observation period. Mean age was 55 at base line, and 66 at the end of the follow up. During the entire 13.3 years follow-up, the mortality in the intensive-therapy group was $30 \%$ compared to $50 \%$ in the conventional therapy group, an absolute risk-reduction of $20 \%$. Additionally, the risk of overt diabetic nephropathy or ESRD was significantly reduced in the intensivetherapy group. This study highlights the need for targeting multiple pathways in order to reduce the burden of diabetic complications. The Antithrombotic Trialists' Collaboration [114] demonstrated in a meta analysis that aspirin reduced nonfatal MI, nonfatal, stroke, and vascular death by approximately one third, irrespective of age or diabetic condition. They also showed that low dosage aspirin in hemodialysis patients had a statistically significant $41 \%$ reduction in major cardiovascular end points with similar major extra-cranial bleeding in the general population. Therefore, and in the absence of contraindications, Aspirin (ASA) should be offered to DN patients in a low average dose.

Early referral to nephrologist: Primary care providers are on the front line in our battle against DN. The availability of several guidelines from professional societies, such as the American Diabetes Association, National Kidney Foundation and the American Society of Hypertension has helped a great deal in this fight. The coordinated effort among the different specialties; primary care provider, endocrinologist and nephrologist remains crucial for optimal patient outcomes. Early referral to nephrologists has been found to be associated with decreased rates of decline in GFR [115] and mortality [116]. In spite of that, it is still not uncommon for CKD patients to be seen by a nephrologist for the first time only one month before starting dialysis [117,118]. Similar trends were also noted in Europe, Australia, New Zealand and Canada. Ghossein et al. suggested that the greatest benefit to patients occurs when referral to nephrologist is initiated before the plasma creatinine concentration exceeds 1.5 to $2 \mathrm{mg} / \mathrm{dL}$ or GFR is less than $60 \mathrm{~mL} / \mathrm{min}$ per $1.73 \mathrm{~m}^{2}$ [119]. Early referral to nephrologist is also important for the elderly patients. Nephrologists need to present elderly patients with advanced CKD and their families the available treatment options and establish, through shared decision making, realistic goals of therapy. Nephrologists also need to discuss end of life care options available to the elderly patients, particularly those with multiple co-morbidities and poor quality of life.

\section{Summary and Conclusion}

Elderly patients represent a unique group of patients who require a more tailored therapy to avoid further co-morbidities (Table 1). Strategies for the early identification and treatment of DN in elderly have evolved based on new clinical trials. The current evidence-based

Exercise and weight reduction might not be applicable in elderly patients Blood sugar Control

Less stringent $\mathrm{A} 1 \mathrm{C}$ target.

Selective hypoglycemic agents and doses.

Blood Pressure Control

Treat BP $>140 / 80 \mathrm{~mm} \mathrm{Hg}$

Avoid Hypotension and associated risk of falls.

Caution when using RAAS blockers in elderly. Greater risk of AKI, hyperkalemia and hypotension.

Nondihydropyridine Calcium Channel Blockers (Dccbs), such as diltiazem, verapamil can be used in elderly diabetic patients with albuminuria and nephropathy who are unable to tolerate ACEls or ARBs.

Beta-blockers and diuretics may be helpful in the management of DN in elderly, but should probably be used in combination with ACEi or ARBs.

Table 1: Unique Characteristics in Management of Elderly with DN. 
approaches place emphasis on individualizing optimal glycemic control, BP control with RAAS-blockade as first-line agents, and optimization of traditional cardiovascular risk factors. Successful outcomes can be achieved with treatment that incorporates the aforementioned multifaceted interventions to slow the progression of diabetic renal disease and its associated complications.

\section{References}

1. Resnick HE, Harris MI, Brock DB, Harris TB (2000) American Diabetes Association diabetes diagnostic criteria, advancing age, and cardiovascular disease risk profiles: results from the Third National Health and Nutrition Examination Survey. Diabetes Care 23: 176-180.

2. Cowie CC, Rust KF, Ford ES, Eberhardt MS, Byrd-Holt DD, et al. (2009) Ful accounting of diabetes and pre-diabetes in the U.S. population in 1988-1994 and 2005-2006. Diabetes Care 32: 287-294.

3. Orimo H, Ito H, Suzuki T, Araki A, Hosoi T, et al. (2006) Reviewing the definition of "elderly". Geriatr Gerontol Int 6: 149-158.

4. (2005) USRDS TUSRDS. Annual Data Report, Bethesda, The National Institutes of Diabetes and Digestive and Kidney Diseases.

5. Luño J, Garcia de Vinuesa S, Gomez-Campdera F, Lorenzo I, Valderrábano F (1998) Effects of antihypertensive therapy on progression of diabetic nephropathy. Kidney Int 68: 112-119.

6. Eknoyan G, Hostetter T, Bakris GL, Hebert L, Levey AS, et al. (2003) Proteinuria and other markers of chronic kidney disease: a position statement of the national kidney foundation (NKF) and the national institute of diabetes and digestive and kidney diseases (NIDDK). Am J Kidney Dis 42: 617-622.

7. Adler S (2004) Diabetic nephropathy: Linking histology, cell biology, and genetics. Kidney Int 66: 2095-2106.

8. Raptis AE, Viberti G (2001) Pathogenesis of diabetic nephropathy. Exp Clin Endocrinol Diabetes 109: S424-437.

9. (2009) Standards of medical care in diabetes-2009. Diabetes Care 32: 13-61.

10. Gaede P, Vedel P, Parving HH, Pedersen O (1999) Intensified multifactorial intervention in patients with type 2 diabetes mellitus and microalbuminuria: the Steno type 2 randomised study. Lancet 353: 617-622.

11. Beulens JW, Kruidhof JS, Grobbee DE, Chaturvedi N, Fuller JH, et al. (2008) Alcohol consumption and risk of microvascular complications in type 1 diabetes patients: the EURODIAB Prospective Complications Study. Diabetologia 51: $1631-1638$.

12. Morley JE (2007) Weight loss in the nursing home. J Am Med Dir Assoc 8 : 201-204

13. MacIntosh C, Morley JE, Chapman IM (2000) The anorexia of aging. Nutrition 16: $983-995$

14. Amiel SA, Dixon T, Mann R, Jameson K (2008) Hypoglycaemia in Type 2 diabetes. Diabet Med 25: 245-254.

15. Action to Control Cardiovascular Risk in Diabetes Study Group, Gerstein HC, Miller ME, Byington RP, Goff DC Jr, et al. (2008) Effects of intensive glucose lowering in type 2 diabetes. N Engl J Med 358: 2545-2559.

16. ADVANCE Collaborative Group, Patel A, MacMahon S, Chalmers J, Neal B, et al. (2008) Intensive blood glucose control and vascular outcomes in patients with type 2 diabetes. N Engl J Med 358: 2560-2572.

17. Duckworth W, Abraira C, Moritz T, Reda D, Emanuele N, et al. (2009) Glucose control and vascular complications in veterans with type 2 diabetes. $\mathrm{N}$ Engl J Med 360: 129-139.

18. Biesenbach G, Raml A, Schmekal B, Eichbauer-Sturm G (2003) Decreased insulin requirement in relation to GFR in nephropathic Type 1 and insulintreated Type 2 diabetic patients. Diabet Med 20: 642-645.

19. Duong JK, Roberts DM, Furlong TJ, Kumar SS, Greenfield JR, et al. (2012) Metformin therapy in patients with chronic kidney disease. Diabetes Obes Metab.

20. Lipscombe LL, Gomes T, Lévesque LE, Hux JE, Juurlink DN, et al. (2007) Thiazolidinediones and cardiovascular outcomes in older patients with diabetes. JAMA 298: 2634-2643.

21. Dhillon S (2010) Sitagliptin: a review of its use in the management of type 2 diabetes mellitus. Drugs 70: 489-512.
22. Barzilai N, Mahoney EM, Guo H, Lu K, Golm GT, et al. (2009) Sitagliptin is well tolerated and leads to rapid improvement in blood glucose in the first days of monotherapy in patients aged 65 years and older with T2DM. Diabetes 58: 158

23. Chan JC, Scott R, Arjona Ferreira JC, Sheng D, Gonzalez E, et al. (2008) Safety and efficacy of sitagliptin in patients with type 2 diabetes and chronic renal insufficiency. Diabetes Obes Metab 10: 545-555.

24. (1993) Hypertension in Diabetes Study (HDS): I. Prevalence of hypertension in newly presenting type 2 diabetic patients and the association with risk factors for cardiovascular and diabetic complications. J Hypertens 11: 309-317.

25. Mogensen CE (1982) Long-term antihypertensive treatment inhibiting progression of diabetic nephropathy. Br Med J (Clin Res Ed) 285: 685-688.

26. Schrier RW, Estacio RO, Esler A, Mehler P (2002) Effects of aggressive blood pressure control in normotensive type 2 diabetic patients on albuminuria retinopathy and strokes. Kidney Int 61: 1086-1097.

27. (1998) Tight blood pressure control and risk of macrovascular and microvascula complications in type 2 diabetes: UKPDS 38. UK Prospective Diabetes Study Group. BMJ 317: 703-713.

28. (1998) Cost effectiveness analysis of improved blood pressure control in hypertensive patients with type 2 diabetes: UKPDS 40. UK Prospective Diabetes Study Group. BMJ 317: 720-726

29. Patel A, MacMahon S, Chalmers J, Neal B, Woodward M, et al. (2007) Effects of a fixed combination of perindopril and indapamide on macrovascula and microvascular outcomes in patients with type 2 diabetes mellitus (the ADVANCE trial): a randomised controlled trial. Lancet 370: 829-840.

30. de Galan BE, Perkovic V, Ninomiya T, Pillai A, Patel A, et al. (2009) Lowering blood pressure reduces renal events in type 2 diabetes. J Am Soc Nephrol 20 883-892.

31. Chobanian AV, Bakris GL, Black HR, Cushman WC, Green LA, et al. (2003) Seventh report of the Joint National Committee on Prevention, Detection, Evaluation, and Treatment of High Blood Pressure. Hypertension 42: 12061252.

32. American Diabetes Association (2005) Standards of medical care in diabetes. Diabetes Care 28: S4-4S36.

33. Kidney Disease Outcomes Quality Initiative (K/DOQI) (2004) K/DOQI clinica practice guidelines on hypertension and antihypertensive agents in chronic kidney disease. Am J Kidney Dis 43: S1-290.

34. Cushman WC, Evans GW, Byington RP, Goff DC Jr, Grimm RH Jr, et al. (2010) Effects of Intensive Blood-Pressure Control in Type 2 Diabetes Mellitus. N Eng J Med 362: 1575-1585.

35. Schrier RW, Estacio RO, Jeffers B (1996) Appropriate Blood Pressure Control in NIDDM (ABCD) Trial. Diabetologia 39: 1646-1654.

36. Hansson L, Zanchetti A, Carruthers SG, Dahlof B, Elmfeldt D, et al. (1998) Effects of intensive blood-pressure lowering and low-dose aspirin in patients with hypertension: principal results of the Hypertension Optimal Treatment (HOT) randomised trial. HOT Study Group. Lancet 351: 1755-1762.

37. Klahr S, Levey AS, Beck GJ, Caggiula AW, Hunsicker L, et al. (1994) The effects of dietary protein restriction and blood-pressure control on the progression of chronic renal disease. Modification of Diet in Renal Disease Study Group. N Engl J Med 330: 877-884.

38. Wright JT Jr, Bakris G, Greene T, Agodoa LY, Appel LJ, et al. (2002) Effect of blood pressure lowering and antihypertensive drug class on progression of hypertensive kidney disease: results from the AASK trial. JAMA 288: 2421 2431.

39. Sacks FM, Svetkey LP, Vollmer WM, Appel LJ, Bray GA, et al. (2001) Effects on blood pressure of reduced dietary sodium and the Dietary Approaches to Stop Hypertension (DASH) diet. DASH-Sodium Collaborative Research Group. N Engl J Med 344: 3-10.

40. Mogensen CE, Keane WF, Bennett PH, Jerums G, Parving HH, et al. (1995) Prevention of diabetic renal disease with special reference to microalbuminuria. Lancet 346: 1080-1084.

41. Kasiske BL, Kalil RS, Ma JZ, Liao M, Keane WF (1993) Effect of antihypertensive therapy on the kidney in patients with diabetes: a meta-regression analysis. Ann Intern Med 118: 129-138.

42. Nilsson PM, Cederholm J (2011) Diabetes, hypertension, and outcome studies: overview 2010. Diabetes Care 34: S109-113. 
43. ACCORD Study Group, Cushman WC, Evans GW, Byington RP, Goff DC Jr, et al. (2010) Effects of intensive blood-pressure control in type 2 diabetes mellitus. N Engl J Med 362: 1575-1585.

44. Cooper-DeHoff RM, Gong Y, Handberg EM, Bavry AA, Denardo SJ, et al. (2010) Tight blood pressure control and cardiovascular outcomes among hypertensive patients with diabetes and coronary artery disease. JAMA 304: 61-68.

45. Cederholm J, Gudbjornsdottir S, Eliasson B, Zethelius B, Eeg-Olofsson K, et al. (2010) Systolic blood pressure and risk of cardiovascular diseases in type 2 diabetes: an observational study from the Swedish national diabetes register. J Hypertens 28: 2026-2035.

46. Brown AF, Mangione CM, Saliba D, Sarkisian CA; California Healthcare Foundation/American Geriatrics Society Panel on Improving Care for Elders with Diabetes (2003) Guidelines for improving the care of the older person with diabetes mellitus. J Am Geriatr Soc 51: S265-280.

47. Sinclair AJ, Paolisso G, Castro M, Bourdel-Marchasson I, Gadsby R, et al (2011) European Diabetes Working Party for Older People 2011 clinical guidelines for type 2 diabetes mellitus. Executive summary. Diabetes Metab 37: S27-38.

48. Wu JS, Yang YC, Lu FH, Wu CH, Wang RH, et al. (2009) Population-based study on the prevalence and risk factors of orthostatic hypotension in subjects with pre-diabetes and diabetes. Diabetes Care 32: 69-74.

49. Dunn MJ (1990) Prostaglandins, angiotension II, and proteinuria. Nephron 55 30-37.

50. Melchior WR, Bindlish V, Jaber LA (1993) Angiotensin-converting enzyme inhibitors in diabetic nephropathy. Ann Pharmacother 27: 344-350.

51. Mann JF, Schmieder RE, Dyal L, McQueen MJ, Schumacher H, et al. (2009) Effect of telmisartan on renal outcomes: a randomized trial. Ann Intern Med 151: 1-10.

52. Barnett AH, Bain SC, Bouter P, Karlberg B, Madsbad S, et al. (2004) Angiotensin-receptor blockade versus converting-enzyme inhibition in type 2 diabetes and nephropathy. N Engl J Med 351: 1952-1961.

53. Ahmed AK, Kamath NS, El Kossi M, El Nahas AM (2010) The impact of stopping inhibitors of the renin-angiotensin system in patients with advanced chronic kidney disease. Nephrol Dial Transplant 25: 3977-3982.

54. Baraldi A, Ballestri M, Rapanà R, Lucchi L, Borella $P$, et al. (1998) Acute renal failure of medical type in an elderly population. Nephrol Dial Transplant 13 $25-29$.

55. Messerli FH, Sundgaard-Riise K, Ventura HO, Dunn FG, Glade LB, et al. (1983) Essential hypertension in the elderly: haemodynamics, intravascular volume, plasma renin activity, and circulating catecholamine levels. Lancet 2: 983-986.

56. Kunz R, Friedrich C, Wolbers M, Mann JF (2008) Meta-analysis: effect of monotherapy and combination therapy with inhibitors of the renin angiotensin system on proteinuria in renal disease. Ann Intern Med 148: 30-48.

57. Mann JF, Schmieder RE, McQueen M, Dyal L, Schumacher H, et al. (2008) Renal outcomes with telmisartan, ramipril, or both, in people at high vascular risk (the ONTARGET study): a multicentre, randomised, double-blind, controlled trial. Lancet 372: 547-553.

58. (1997) Randomised placebo-controlled trial of lisinopril in normotensive patients with insulin-dependent diabetes and normoalbuminuria or microalbuminuria The EUCLID Study Group. Lancet 349: 1787-1792.

59. Ravid M, Brosh D, Levi Z, Bar-Dayan Y, Ravid D, et al. (1998) Use of enalapri to attenuate decline in renal function in normotensive, normoalbuminuric patients with type 2 diabetes mellitus. A randomized, controlled trial. Ann Intern Med 128: 982-988.

60. Estacio RO, Jeffers BW, Gifford N, Schrier RW (2000) Effect of blood pressure control on diabetic microvascular complications in patients with hypertension and type 2 diabetes. Diabetes Care 23: B54-64.

61. Ravid M, Savin H, Jutrin I, Bental T, Katz B, et al. (1993) Long-term stabilizing effect of angiotensin-converting enzyme inhibition on plasma creatinine and on proteinuria in normotensive type II diabetic patients. Ann Intern Med 118 $577-581$

62. Andersen S, Tarnow L, Rossing P, Hansen BV, Parving HH (2000) Renoprotective effects of angiotensin II receptor blockade in type 1 diabetic patients with diabetic nephropathy. Kidney Int 57: 601-606.

63. Brenner BM, Cooper ME, de Zeeuw D, Keane WF, Mitch WE, et al. (2001)
Effects of losartan on renal and cardiovascular outcomes in patients with type 2 diabetes and nephropathy. N Engl J Med 345: 861-869.

64. Lewis EJ, Hunsicker LG, Clarke WR, Berl T, Pohl MA, et al. (2001) Renoprotective effect of the angiotensin-receptor antagonist irbesartan in patients with nephropathy due to type 2 diabetes. N Engl J Med 345: 851-860.

65. Parving $\mathrm{HH}$, Lehnert $\mathrm{H}$, Bröchner-Mortensen J, Gomis R, Andersen S, et al (2001) The effect of irbesartan on the development of diabetic nephropathy in patients with type 2 diabetes. N Engl J Med 345: 870-878.

66. Lewis EJ, Hunsicker LG, Bain RP, Rohde RD (1993) The effect of angiotensinconverting-enzyme inhibition on diabetic nephropathy. The Collaborative Study Group. N Engl J Med 329: 1456-1462.

67. van den Meiracker $A H$, Man in 't Veld AJ, Admiraal PJ, Ritsema van Eck HJ, Boomsma F, et al. (1992) Partial escape of angiotensin converting enzyme (ACE) inhibition during prolonged ACE inhibitor treatment: does it exist and does it affect the antihypertensive response? J Hypertens 10: 803-812.

68. Bomback AS, Klemmer PJ (2007) The incidence and implications of aldosterone breakthrough. Nat Clin Pract Nephrol 3: 486-492.

69. Ingelfinger JR (2008) Aliskiren and dual therapy in type 2 diabetes mellitus. N Engl J Med 358: 2503-2505.

70. Nussberger J, Wuerzner G, Jensen C, Brunner HR (2002) Angiotensin II suppression in humans by the orally active renin inhibitor Aliskiren (SPP100): comparison with enalapril. Hypertension 39: E1-8.

71. Azizi M, Ménard J, Bissery A, Guyenne TT, Bura-Rivière A, et al. (2004) Pharmacologic demonstration of the synergistic effects of a combination of the renin inhibitor aliskiren and the AT1 receptor antagonist valsartan on the angiotensin II-renin feedback interruption. J Am Soc Nephrol 15: 3126-3133.

72. Azizi M, Ménard J, Bissery A, Guyene TT, Bura-Rivière A (2007) Hormonal and hemodynamic effects of aliskiren and valsartan and their combination in sodium-replete normotensive individuals. Clin J Am Soc Nephrol 2: 947-955.

73. Parving HH, Persson F, Lewis JB, Lewis EJ, Hollenberg NK, et al. (2008) Aliskiren combined with losartan in type 2 diabetes and nephropathy. $\mathrm{N} \mathrm{Engl}$ Med 358: 2433-2446.

74. Mehdi UF, Adams-Huet B, Raskin P, Vega GL, Toto RD (2009) Addition of angiotensin receptor blockade or mineralocorticoid antagonism to maxima angiotensin-converting enzyme inhibition in diabetic nephropathy. J Am Soc Nephrol 20: 2641-2650.

75. Sato A, Hayashi K, Saruta T (2005) Antiproteinuric effects of mineralocorticoid receptor blockade in patients with chronic renal disease. Am J Hypertens 18 44-49.

76. Pitt B, Zannad F, Remme WJ, Cody R, Castaigne A, et al. (1999) The effect of spironolactone on morbidity and mortality in patients with severe heart failure. Randomized Aldactone Evaluation Study Investigators. N Engl J Med 341: 709 717 .

77. Ozkara A, Turgut F, Selcoki Y, Karanfil A, Metin MR, et al. (2007) Probrain natriuretic peptide for assessment of efficacy in heart failure treatment. Adv Ther 24: 1233-1239.

78. Tuomilehto J, Rastenyte D, Birkenhäger WH, Thijs L, Antikainen R, et al (1999) Effects of calcium-channel blockade in older patients with diabetes and systolic hypertension. Systolic Hypertension in Europe Trial Investigators. N Engl J Med 340: 677-684

79. Svensson M, Gustafsson F, Galatius S, Hildebrandt PR, Atar D (2004) How prevalent is hyperkalemia and renal dysfunction during treatment with spironolactone in patients with congestive heart failure? J Card Fail 10: 297303.

80. Tamirisa KP, Aaronson KD, Koelling TM (2004) Spironolactone-induced rena insufficiency and hyperkalemia in patients with heart failure. Am Heart J 148 971-978

81. Pitt B, Remme W, Zannad F, Neaton J, Martinez F, et al. (2003) Eplerenone, a selective aldosterone blocker, in patients with left ventricular dysfunction after myocardial infarction. N Engl J Med 348: 1309-1321.

82. Hollenberg NK, Williams GH, Anderson R, Akhras KS, Bittman RM, et al. (2003) Symptoms and the distress they cause: comparison of an aldosterone antagonist and a calcium channel blocking agent in patients with systolic hypertension. Arch Intern Med 163: 1543-1548.

83. McMurray JJ, Pitt B, Latini R, Maggioni AP, Solomon SD, et al. (2008) Effects of 
Citation: Abdel-Rahman EM, Alhamad T, Brian Reeves W, Awad AS (2012) Management of Diabetic Nephropathy in the Elderly: Special Considerations. J Nephrol Therapeut 2:124. doi:10.4172/2161-0959.1000124

Page 8 of 8

the oral direct renin inhibitor aliskiren in patients with symptomatic heart failure. Circ Heart Fail 1: 17-24.

84. Sato A, Hayashi K, Naruse M, Saruta T (2003) Effectiveness of aldosterone blockade in patients with diabetic nephropathy. Hypertension 41: 64-68.

85. Rossing K, Schjoedt KJ, Smidt UM, Boomsma F, Parving HH (2005) Beneficia effects of adding spironolactone to recommended antihypertensive treatment in diabetic nephropathy: a randomized, double-masked, cross-over study. Diabetes Care 28: 2106-2112

86. Rachmani R, Slavachevsky I, Amit M, Levi Z, Kedar Y, et al. (2004) The effect of spironolactone, cilazapril and their combination on albuminuria in patients with hypertension and diabetic nephropathy is independent of blood pressure reduction: a randomized controlled study. Diabet Med 21: 471-475.

87. Bakris GL, Weir MR, Secic M, Campbell B, Weis-McNulty A (2004) Differentia effects of calcium antagonist subclasses on markers of nephropathy progression. Kidney Int 65: 1991-2002.

88. Remuzzi G, Ruggenenti P, Benigni A (1997) Understanding the nature of rena disease progression. Kidney Int 51: 2-15.

89. Kloke HJ, Branten AJ, Huysmans FT, Wetzels JF (1998) Antihypertensive treatment of patients with proteinuric renal diseases: risks or benefits of calcium channel blockers? Kidney Int 53: 1559-1573.

90. Gansevoort RT, Sluiter WJ, Hemmelder MH, de Zeeuw D, de Jong PE (1995) Antiproteinuric effect of blood-pressure-lowering agents: a meta-analysis of comparative trials. Nephrol Dial Transplant 10: 1963-1974.

91. Bakris GL, Copley JB, Vicknair N, Sadler R, Leurgans S (1996) Calcium channel blockers versus other antihypertensive therapies on progression of NIDDM associated nephropathy. Kidney Int 50: 1641-1650.

92. Bakris GL, Mangrum A, Copley JB, Vicknair N, Sadler R (1997) Effect of calcium channel or beta-blockade on the progression of diabetic nephropathy in African Americans. Hypertension 29: 744-750.

93. Nielsen FS, Rossing P, Gall MA, Skøtt P, Smidt UM, et al. (1997) Long-term effect of lisinopril and atenolol on kidney function in hypertensive NIDDM subjects with diabetic nephropathy. Diabetes 46: 1182-1188.

94. (1998) Efficacy of atenolol and captopril in reducing risk of macrovascular and microvascular complications in type 2 diabetes: UKPDS 39. UK Prospective Diabetes Study Group. BMJ 317: 713-720.

95. Curb JD, Pressel SL, Cutler JA, Savage PJ, Applegate WB, et al. (1996) Effect of diuretic-based antihypertensive treatment on cardiovascular disease risk in older diabetic patients with isolated systolic hypertension. Systolic Hypertension in the Elderly Program Cooperative Research Group. JAMA 276: 1886-1892.

96. Marre M, Puig JG, Kokot F, Fernandez M, Jermendy G, et al. (2004) Equivalence of indapamide SR and enalapril on microalbuminuria reduction in hypertensive patients with type 2 diabetes: the NESTOR Study. J Hypertens 22: 1613-1622.

97. Bakris GL, Toto RD, McCullough PA, Rocha R, Purkayastha D, et al. (2008) Effects of different ACE inhibitor combinations on albuminuria: results of the GUARD study. Kidney Int 73: 1303-1309.

98. Bakris GL, Sarafidis PA, Weir MR, Dahlöf B, Pitt B, et al. (2010) Renal outcomes with different fixed-dose combination therapies in patients with hypertension at high risk for cardiovascular events (ACCOMPLISH): a prespecified secondary analysis of a randomised controlled trial. Lancet 375: 1173-1181.

99. (2003) National Kidney Foundation: K/DOQI clinical practice guidelines for managing dyslipidemias in chronic kidney disease. Am J Kidney Dis 41: 1-92.

100. O’Brien T, Nguyen TT, Zimmerman BR (1998) Hyperlipidemia and diabetes mellitus. Mayo Clin Proc 73: 969-976.

101. Ginsberg HN (2006) REVIEW: Efficacy and mechanisms of action of statins in the treatment of diabetic dyslipidemia. J Clin Endocrinol Metab 91: 383-392.

102.Zarowitz BJ, Tangalos EG, Hollenack K, Terry O'Shea (2006) The application of evidence-based principles of care in older persons (issue 3): management of diabetes mellitus. JAMDA 7: 234-240.

103. Koka M, Joseph J, Aronow WS (2007) Prevalence of adequate and of optima control of serum low-density lipoprotein cholesterol in an academic nursing home. J Am Med Dir Assoc 8: 604-606.

104. Koskinen P, Mänttäri M, Manninen V, Huttunen JK, Heinonen OP, et al. (1992) Coronary heart disease incidence in NIDDM patients in the Helsinki Heart Study. Diabetes Care 15: 820-825.

105. Downs JR, Clearfield M, Weis S, Whitney E, Shapiro DR, et al. (1998) Primary prevention of acute coronary events with lovastatin in men and women with verage cholesterol levels: results of AFCAPS/TexCAPS. Air Force/Texas Coronary Atherosclerosis Prevention Study. JAMA 279: 1615-1622.

106. ALLHAT Officers and Coordinators for the ALLHAT Collaborative Research Group (2002) Major outcomes in moderately hypercholesterolemic hypertensive patients randomized to pravastatin vs usual care: The Antihypertensive and Lipid-Lowering Treatment to Prevent Heart Attack Trial (ALLHAT-LLT). JAMA 288: 2998-3007.

107. Heart Protection Study Collaborative Group (2002) MRC/BHF Heart Protection Study of cholesterol lowering with simvastatin in 20,536 high-risk individuals: a randomised placebo-controlled trial. Lancet 360: 7-22

108. Collins R, Armitage J, Parish S, Sleigh P, Peto R; Heart Protection Study Collaborative Group (2003) MRC/BHF Heart Protection Study of cholesterollowering with simvastatin in 5963 people with diabetes: a randomised placebocontrolled trial. Lancet 361: 2005-2016.

109. Shepherd J, Blauw GJ, Murphy MB, Bollen EL, Buckley BM, et al. (2002) Pravastatin in elderly individuals at risk of vascular disease (PROSPER): a randomised controlled trial. Lancet 360: 1623-1630.

110. Sever PS, Poulter NR, Dahlof B, Wedel H, Collins R, et al. (2005) Reduction in cardiovascular events with atorvastatin in 2,532 patients with type 2 diabetes: Anglo-Scandinavian Cardiac Outcomes Trial--lipid-lowering arm (ASCOTLLA). Diabetes Care 28: 1151-1157.

111. Vijan S, Hayward RA; American College of Physicians (2004) Pharmacologic lipid-lowering therapy in type 2 diabetes mellitus: background paper for the American College of Physicians. Ann Intern Med 140: 650-658.

112. Baigent C, Landray MJ, Reith C, Emberson J, Wheeler DC, et al. (2011) The effects of lowering LDL cholesterol with simvastatin plus ezetimibe in patients with chronic kidney disease (Study of Heart and Renal Protection): a randomised placebo-controlled trial. Lancet 377: 2181-2192.

113. Gaede P, Lund-Andersen H, Parving HH, Pedersen O (2008) Effect of a multifactorial intervention on mortality in type 2 diabetes. N Engl J Med 358 : 580-591.

114. Antithrombotic Trialists' Collaboration (2002) Collaborative meta-analysis of randomised trials of antiplatelet therapy for prevention of death, myocardial infarction, and stroke in high risk patients. BMJ 324: 71-86.

115. Jones C, Roderick P, Harris S, Rogerson M (2006) Decline in kidney function before and after nephrology referral and the effect on survival in moderate to advanced chronic kidney disease. Nephrol Dial Transplant 21: 2133-2143.

116. Chan MR, Dall AT, Fletcher KE, Lu N, Trivedi H (2007) Outcomes in patients with chronic kidney disease referred late to nephrologists: a meta-analysis. Am J Med 120: 1063-1070.

117. Avorn J, Bohn RL, Levy E, Levin R, Owen WF Jr, et al. (2002) Nephrologist care and mortality in patients with chronic renal insufficiency. Arch Intern Med 162: 2002-2006.

118. Kinchen KS, Sadler J, Fink N, Brookmeyer R, Klag MJ, et al. (2002) The timing of specialist evaluation in chronic kidney disease and mortality. Ann Intern Med 137: 479-486.

119. Ghossein C, Serrano A, Rammohan M, Batlle D (2002) The role of comprehensive renal clinic in chronic kidney disease stabilization and management: The Northwestern experience. Semin Nephrol 22: 526-532. 